(c) 2008 Elsevier Ltd All rights reserved.

\title{
A status report on delamination resistance testing of polymer-matrix composites
}

\author{
A.J. Brunner ${ }^{1,{ }^{*}}$, B.R.K. Blackman ${ }^{2}$, P. Davies ${ }^{3}$ \\ ${ }^{1}$ Materials and Engineering, Empa, Swiss Federal Laboratories for Materials Testing and Research, $\mathrm{CH}-8600$ \\ Dübendorf, Switzerland \\ ${ }^{2}$ Department of Mechanical Engineering, Imperial College London, South Kensington Campus, London, SW7 \\ 2AZ, UK \\ ${ }^{3}$ Materials \& Structures Group, IFREMER, Centre de Brest, BP70, F-29280 Plouzané, France \\ *: Corresponding author: A.J. Brunner, phone +41 4482344 93, fax +41 4482162 44, e-mail \\ andreas.brunner@empa.ch
}

\begin{abstract}
:
The development of fracture mechanics test methods for the determination of delamination resistance or fracture toughness of fiber-reinforced, polymer-matrix composites is an active area of research. The emphasis in this review is on standardisation of test methods. Recent developments leading towards new standardized test procedures will be presented, complementing and updating earlier reviews.
\end{abstract}

Keywords: fracture toughness, delamination resistance, polymer-matrix composites, test procedure, standards, review 


\section{Introduction}

The status of the development of test methods for fracture mechanics properties of fiber-reinforced, polymer-matrix composites (FRPC) around the millennium has been reviewed by Davies et al. [1] and Tay [2]. The present contribution will focus on more recent developments and provide an update on these earlier reviews. For the ease of comparison, it will be organized similar to the review by Davies et al. [1]. The emphasis will be on experimental work, i.e., the development of test methods that have been recently standardised, are currently being considered for standardisation, or are under development with the aim of proposing them as future standard test methods. There is also extensive research on theoretical developments and modelling in fracture mechanics of FRPC, but a review of these aspects is beyond the scope of the present paper. Modelling aspects are discussed extensively by Tay [2].

It is worthwhile to briefly consider for which purposes delamination resistance data from various laminates can be used. As outlined in [1], comparative assessment of different formulations of matrix materials with respect to improved toughness for materials development, the determination of damage tolerance of composite structures that was perceived to correlate with delamination resistance, and the need to establish critical energy release rates for structural design and calculations are major reasons for the development of standardised test methods. The latter is still limited to a few applications, even though the principal methodology has been established [3]. Quality control in manufacturing or failure analysis of composite parts and structures, in principle, do constitute other areas of application of the standards. While the former may be implemented at some manufacturers (e.g., those publishing data sheets with fracture mechanics values), the latter is rarely used and, to the best of our knowledge, not documented in the literature.

In the area of delamination resistance testing, the concurrent development of test methods for composites and adhesives by the Technical Committee 4 (TC4) Polymers \& Composites of the European Structural Integrity Society (ESIS) is fairly recent. This recognizes the fact that the major problems are the same or analogous in various polymer-based materials. In this respect, it will also be worthwhile to follow the development of test methods for "natural" composite materials, such as wood (see, e.g., [4]). A detailed description of the test procedures developed for FRPC within ESIS TC4 and data determined with these procedures up to 2001 are available in [5].

In the following, the status of delamination resistance test method development is briefly reviewed and recent developments are discussed. The sequence of sections will follow the mode of loading (mode I = opening, mode II = shear, mode III = twisting, various mixed modes) and each section be organized according to the loading-rate (quasi-static, fatigue, high-rate).

\section{MODE I TESTING}

A mode I (opening) test method for delamination resistance has finally been accepted as an international standard by ISO in 2001 [6]. The test method published by the American Society for Testing and Materials (ASTM) in 1994 [7] is, in a revised version issued in 2001, technically equivalent to the ISO test. The mode I standard test method issued in 1993 together with a mode II procedure by the Japanese Standards Association [8] is similar, but not identical to the ISO and ASTM procedures. For details on the earlier approaches, the reader is referred to [1].

The preferred specimen type in most mode I tests is the so-called Double Cantilever Beam (DCB), schematically shown in Fig. 1. A non-sticking, thin film insert acts as starter crack (recommended to be less than $13 \mu \mathrm{m}$ thick). Tensile load to open the starter crack and to promote delamination through the mid-beam interlaminar layer is introduced via two load-blocks at quasi-static cross-head displacements between 1 and $5 \mathrm{~mm} / \mathrm{min}$. Delamination lengths are determined visually during the test, the use of a travelling microscope for more accurate delamination length readings is optional, but recommended. The data analysis is either based on beam theory (with corrections for loadblocks and large displacements) or on experimental compliance calibration [6].

An earlier alternative for a mode I delamination resistance test was based on a setup where either a wedge was driven into a starter crack or a pre-cracked specimen was driven against a stationary wedge [9]. There are obvious problems with the proposed version, e.g., the neglect of friction effects in the analysis and the difficulty of determining delamination initiation. Even though this type of setup never became widely used, it may have some merits in special cases. One of them is the preparation of pre-cracks in laminates without film insert, e.g., for failure analysis [10]. Due to the symmetry in load introduction and setup, a wedge-type test is currently under consideration for a mode I procedure with load rates between 1 and about $10 \mathrm{~m} / \mathrm{s}$ within the ESIS TC4. 
The scope of the ISO standard test method currently limits its application to quasi-static loading of unidirectionally carbon or glass fiber-reinforced thermosets and thermoplastics. Research and development on mode I testing directed towards future standardisation in the years since 2001 mainly concentrated on exploring whether the existing standard method could accommodate conditions or parameters outside the defined limits or whether a modified procedure would be needed to achieve this.

Test parameters for mode I - or, in fact, for any mode or mode mixing - can be explored in many different directions. Major questions are other types of fibers (e.g., aramide or natural fibers such as jute or hemp or of non-unidirectional fiber arrangements (e.g., woven rovings, braided or knitted fabrics, other types of lay-up (e.g., cross-ply, multidirectional), other types of loading (e.g., fatigue, higher rates), other specimen shapes (e.g., with curvature and taper), and testing under other environments (e.g., high and low temperature, respectively, or in different media, such as water). The above list is by no means complete and various combinations of the listed test conditions could also be considered.

In 1989, a review of different types of fiber and matrix, summarized the fracture toughness data for glass- and carbon-fiber reinforced laminates under mode I and mode II loading [11]. Unfortunately, there is no summary of data that have been published since then. Also, many round robin data from test development still remain unpublished. Literature on fracture toughness of Kevlar-based composites is scant (see, e.g., [12-14]) and not all data are from pure Kevlar reinforced laminates. The situation for composites from natural fibers is similar $[15,16]$, even though it is expected that due to increased interest in renewable resources, these materials will gain in importance. There is literature on mode I fracture toughness measurements of glass-mat (e.g., [17]) and various textile glass-reinforced (e.g., [18]) composites, as well as of woven carbon-reinforced laminates (e.g., [19]).
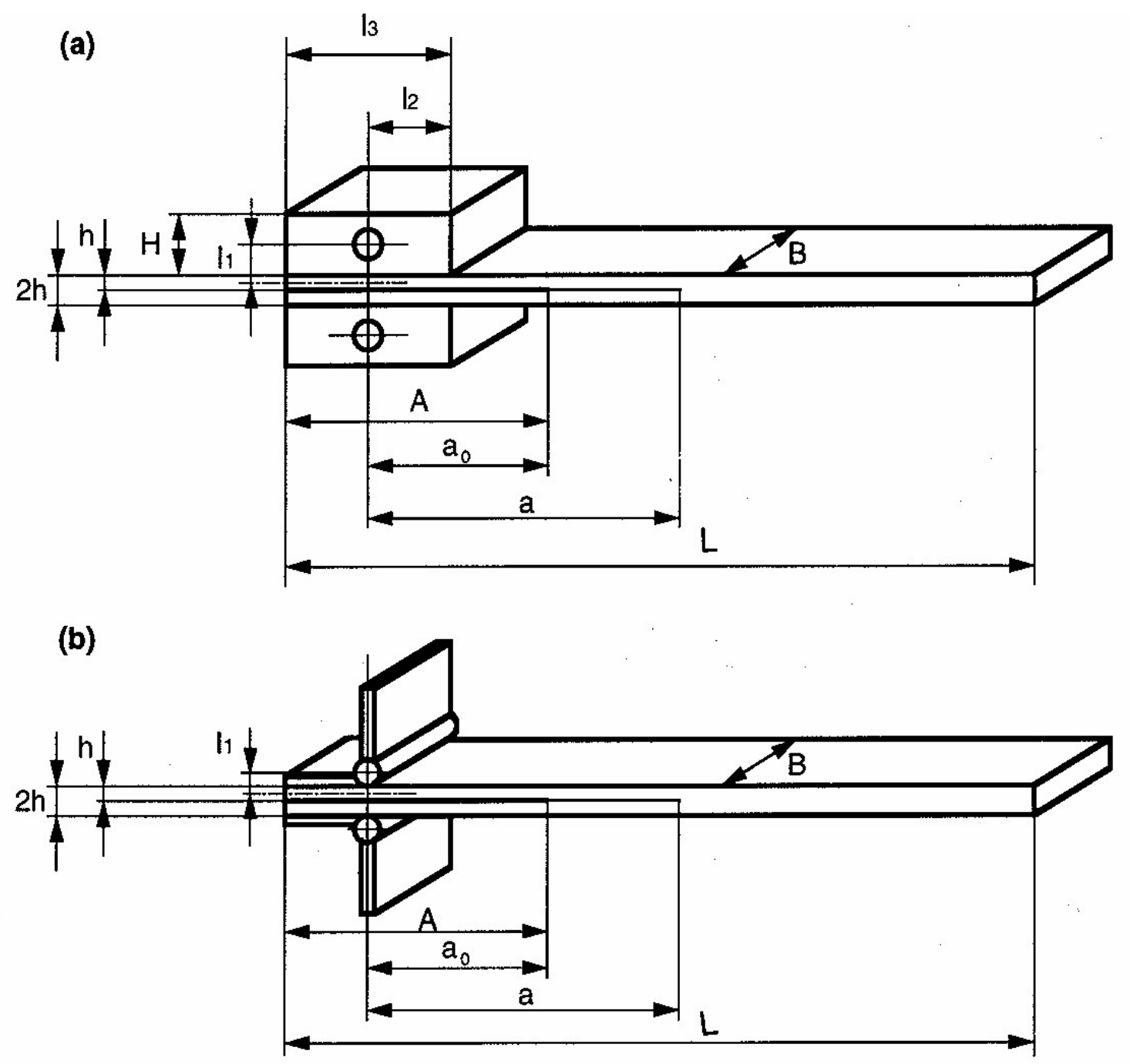

Figure 1: Schematic of the Double Cantilever Beam specimen used for Mode I testing, load blocks (a) or piano hinges (b) can be used for the load introduction [6]. 
Delamination resistance testing of unidirectionally fiber-reinforced composites from man-made fibers has, with the exception of glass- and carbon-fibers, not yet been investigated in round robin studies and hence not been standardised. The same holds for composites made from natural fibers. A priori, there is no obvious reason why composite laminates with other fiber types could not be tested according to the mode I ISO procedure, as long as size and stiffness criteria [6] are fulfilled. Even though most literature on fracture toughness or delamination resistance testing of laminates with other types of fibers [12-16], i.e., not carbon or glass, does not reference any of the standard test methods, the methodology in many cases is equivalent. It can hence be concluded that the standard test method [6] is applicable to composites reinforced with other, unidirectionally aligned fibers.

The applicability of the standard DCB specimen for delamination resistance testing of laminates with multidirectional lay-up has been assessed by Choi et al. [20], and more recently by Morais et al. for carbon- and glass-fiber laminates [21, 22]. Multidirectional lay-ups frequently pose problems because of crack branching and/or deviations of the delamination from the central plane. Both effects invalidate the analysis according to the ISO standard [6]. Delamination resistance from DCB-test on multidirectional laminates can probably be quantified for initiation only. No significant dependence on the delaminating interface (fiber orientation) was observed [22].

Even for cross-ply composites (alternating $0^{\circ}$ and $90^{\circ}$ orientations stacked on top of each other), extensive round robin testing yielded about $50 \%$ of invalid tests due to deviation from the mid-plane [23]. Typically, the delamination path oscillates between adjacent $0^{\circ}$ plies (Figure 2). These specimens yielded initiation values similar to those observed in the corresponding unidirectional laminate and much steeper resistance curves [23], but higher initiation values have been reported also [24]. This increase in apparent delamination resistance does not scale with the increase in delamination area and the mechanisms are not fully clear yet [25]. The observations that initiation values for cross-ply and multidirectional laminates are comparable to those in unidirectional laminates and apparently do not depend on the type of delaminating interface could be due to the observation (made in the case of cross-ply laminates) that the delamination has to propagate a certain distance (around 0.5 to $1 \mathrm{~mm}$, Fig. 2 edge view), before the oscillating pattern forms [25].

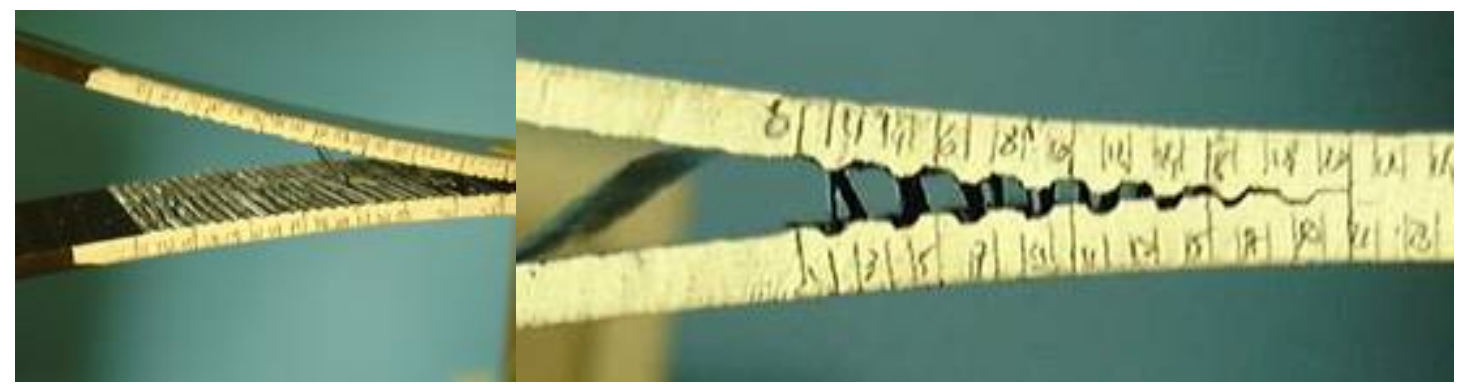

Figure 2: Typical delamination path observed in cross-ply (alternating $0^{\circ} / 90^{\circ}$ layers) laminates, oscillating between adjacent $0^{\circ}$ plies. (Left): view onto fracture surface. (Right): edge view. If delamination paths deviate into the $0^{\circ}$ plies tests are considered invalid.

Clearly, lay-ups with different fiber orientations of the laminate are preferred over unidirectional orientation in most applications and determining experimental data, e.g., for design, still seems to be problematic. Frequently, unidirectional laminates are considered to represent a lower bound but this assumption may discard a considerable part of the design potential of specific multidirectional laminates.

The ASTM D6115 procedure constitutes a first step towards standardisation of other types of loading, namely mode I fatigue [26]. Constant amplitude tension-tension fatigue loading at various G-levels is used to determine delamination growth onset in unidirectional fiber-reinforced laminates. The procedure is based on a limited data base from unidirectional carbon fiber tape laminates with single-phase polymer matrix, as stated in the scope [26]. Fatigue delamination propagation, however, is not considered in this procedure. Within ESIS TC4, there are plans for round robin testing towards a standard test procedure for fatigue delamination propagation with parameters based on published research $[27,28]$. A model for the effect of stress ratio on fatigue delamination under mode I loading has been developed by Andersons et al. [29]. Fatigue life models based on experimental data have also been investigated (e.g., [30, 31]).

High-rate loading typically deals with displacement rates on the order of one to several meters per second. It has to be noted that the speed of the loading device (e.g., cross-head or drop weight) and the resulting delamination speed may be quite different. In Mode I, data for a carbon-fiber epoxy laminate [32] indicate that there are rate-insensitive and rate-sensitive regions of loading rate. The data further show lower fracture toughnesses (about -25\%) at higher loading rates. It is 
hence of interest to develop test methods at higher loading rates. In a unidirectional glass-fiber epoxy laminate, however increasing rate (up to $6 \mathrm{~m} / \mathrm{s}$ ) yielded increasing $G_{I C}$ values [33].

If the DCB-specimen used for quasi-static tests is subjected to higher loading rates, e.g., in a suitable fixture in a drop tower, dynamic effects such as flexural waves propagating in the beam can lead to asymmetric loading situations (Figure 3). This may require a change from the DCBspecimen to a wedge loaded configuration [9]. Preliminary testing for a planned round-robin within ESIS TC4 to determine mode I delamination resistance at load rates between about 1 and $10 \mathrm{~m} / \mathrm{s}$ will involve both, hydraulic test machines and drop towers.

Ballistic impact loading is performed at even higher rates $(10 \mathrm{~m} / \mathrm{s}$ and higher) but typically on plate specimens or parts without starter defects. Damage mechanisms are quite complex. Delamination initiation and growth do occur [34] but quantitative assessment of delamination resistance does not seem feasible from such experiments.

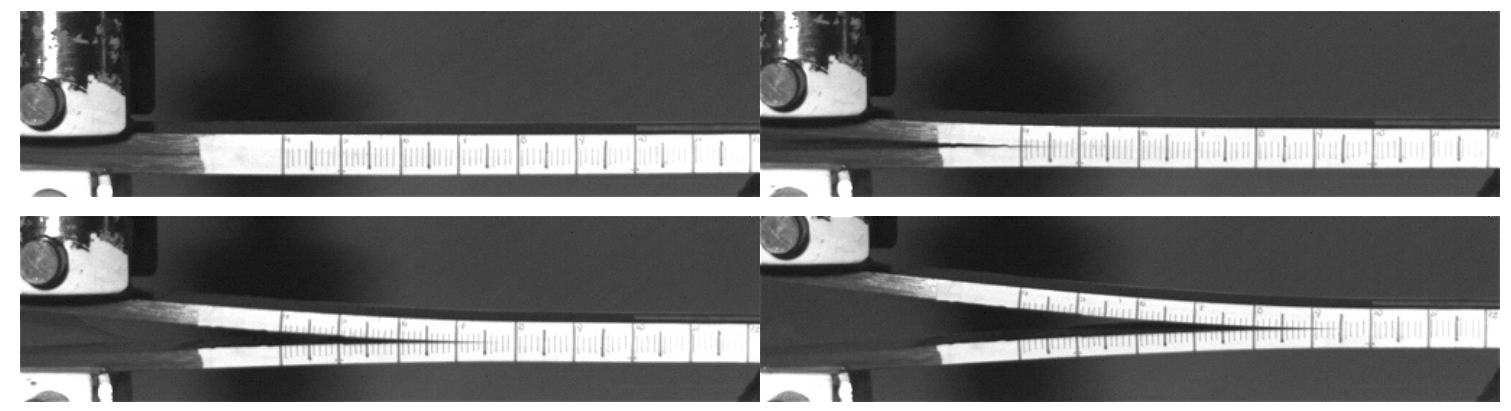

Figure 3: A series of frames selected from a high speed video sequence recorded at 4000 frames per second. The time interval between each frame shown here is $5 \mathrm{~ms}$ (in the film sequence, the frame interval was $250 \mu \mathrm{s}$ ). The photographs are from a DCB-test at $1 \mathrm{~m} / \mathrm{s}$ and even at this relatively moderate loading-rate, an asymmetry is introduced.

\section{MODE II TESTING}

Currently, there exists one Mode II standard test [8] based on the three-point bending end notch flexure (ENF) specimen, since the European Aerospace procedure (prEN6034) is still at the draft stage. Early round robin work on mode II ENF had been conducted jointly by JIS, ASTM and ESIS but, contrary to the situation in mode I, had not resulted in international consensus [1]. Several factors contributed to that. First, the ENF-test is essentially unstable and thus allows only determination of initiation values but not of resistance curves. Second, the question of friction contributions was raised and this resulted in the question whether mode II data were to be regarded as apparent values with no significance as materials data [35].

The four point end notch flexure (4ENF) test was proposed by Martin and Davidson in 1997 [36] and appeared to resolve many of the mode II testing problems. It offered three significant advantages, stable crack propagation, a simple test fixture and a straightforward data analysis. It was evaluated in two round robins organised by VAMAS, involving ASTM, ESIS and JIS participants $[37,38]$. In the first, values of $G_{\| c}$ were compared to values from other mode II tests. In the second a more detailed study of the 4ENF specimen was carried out. There were some anomalous results recorded in these two exercises, notably an apparent decrease in $\mathrm{G}_{\| c}$ with increasing span length, Figure 4.

Another observation from early results was that the $4 E N F$ tended to give values of $G_{\| c}$ significantly higher than those from 3ENF specimens [39].

Nevertheless, overall, and compared to the three other mode II tests examined (ENF, ELS and SENF), the 4ENF specimen appeared satisfactory. Stable propagation was observed, allowing compliance calibration to be made during the test, and results from different laboratories were reasonably consistent (Figure 5).

The test was subsequently used in a number of studies. For example, data analyses were discussed in more detail by Schuecker and Davidson [40]. Results from tests on glass/epoxy specimens were also published [41].

The situation in 2003 , therefore, seemed clear and it appeared to only be a matter of time before the 4ENF specimen would become the standard mode II test method. However, Davidson and colleagues continued to work on the test, in particular trying to understand and explain differences between 3ENF and 4ENF test results. They examined in more detail, for both test configurations, the influence of four factors:

- loading roller diameter 
- $\quad$ specimen geometry

- $\quad$ friction, and

- fixture compliance.

Their conclusions were presented to the ASTM D30 committee in 2004 [42] and are currently being published. First, the roller diameter will contribute to non-linearity as the contact points move and there is a specimen shortening effect. This will be more pronounced in the 4ENF than in the ENF test as the shortening effect comes from both inner and outer rollers. A second related effect is the change in vertical moment arm. Davidson and Sun [43] showed that these effects will cause the ratio of non-linear to linear beam theory values of $G_{\|}$to decrease below one at low loads then to increase above one as loads increase. The specimen geometry (span length) will also affect these non-linearities, but for typical dimensions and roller diameters with carbon/epoxy materials these effects are likely to affect the measured results by less than $5 \%$.

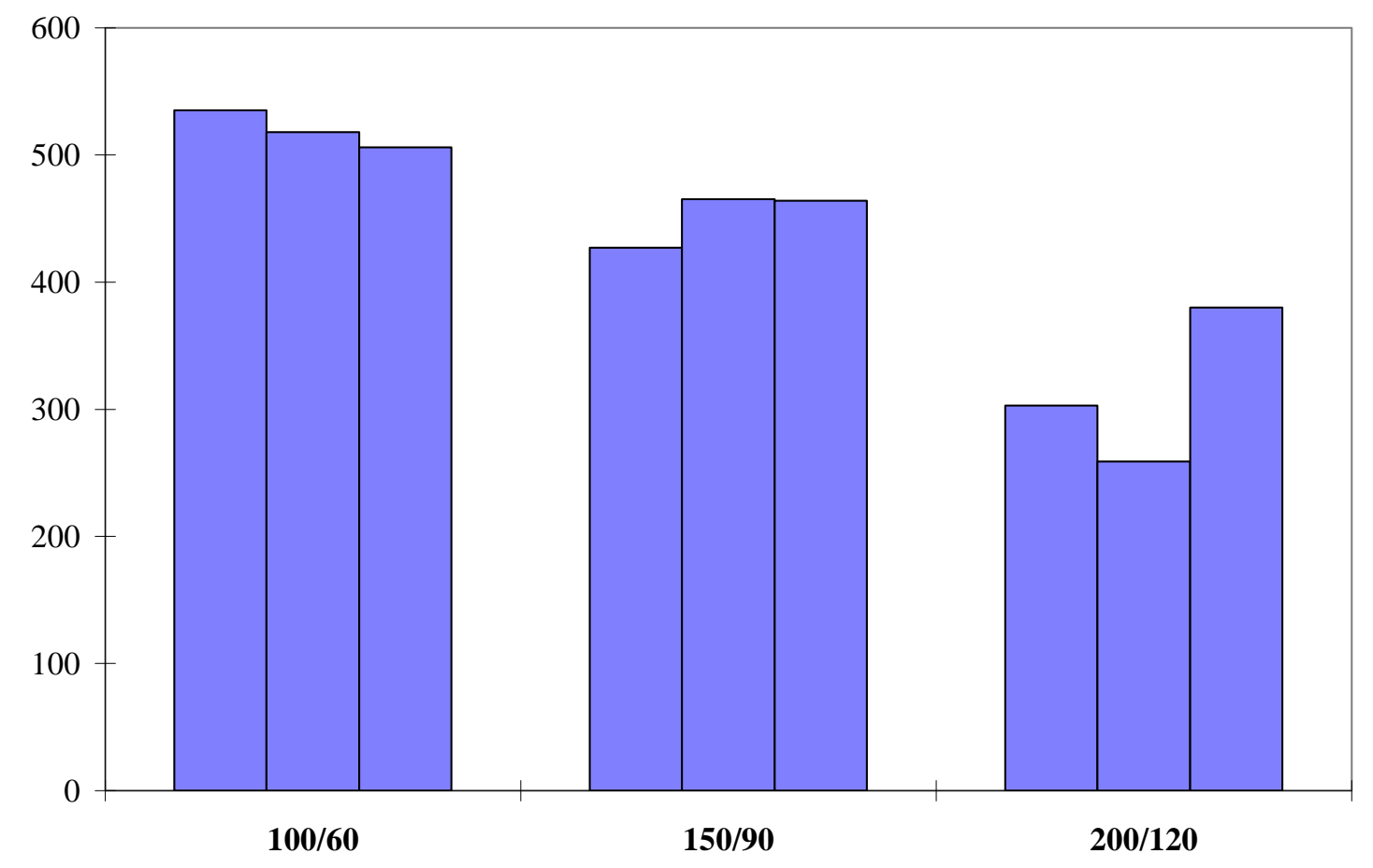

Figure 4. Influence of specimen geometry (lower span/upper span) on initiation values of $\mathrm{G}_{\text {Ilc }}$ (in $\mathrm{J} / \mathrm{m}^{2}$ ) from mode I precrack, brittle carbon/epoxy specimens $3 \mathrm{~mm}$ thick, results from $\mathrm{K}$. Tanaka, University of Toyama, $2^{\text {nd }}$ VAMAS Mode II round robin tests.

The influence of friction in the 3ENF test had been examined numerically previously by Carlsson et al. [44] who concluded that for values of friction coefficient between 0 and 0.5 the influence on $G_{\| c}$ values would be less than $5 \%$ for most cases. For the 4ENF specimen Davidson et al. measured friction coefficient values using a variable wedge fixture which allowed them to increase the wedge angle until samples of half specimens started to slide. They obtained values of 0.374 and 0.345 for two carbon/epoxy materials. When these values were included in numerical analyses it was observed that friction would have a slightly larger influence in the 4ENF specimen than in the 3ENF, but its influence was still minor. It was therefore apparent from these analyses that while all these factors influence the accuracy of results they were not sufficient to explain some of the large differences reported between $\mathrm{G}_{\| \mathrm{c}}$ values from 3ENF and 4ENF tests.

The final aspect examined was fixture compliance. Tests were performed on aluminium bars of different geometries to calibrate the two fixtures. FE analyses then enabled the influence of the fixture compliance to be determined and it was clearly shown that fixture compliance played a very significant role in $\mathrm{G}_{\| \mathrm{Ic}}$ determination. It was also shown that the 4ENF specimen is more sensitive to this, due to the need to include an upper roller bearing. A fixture compliance calibration will be essential if this test is to be used in a standard, but such calibrations are already standard for other tests. 


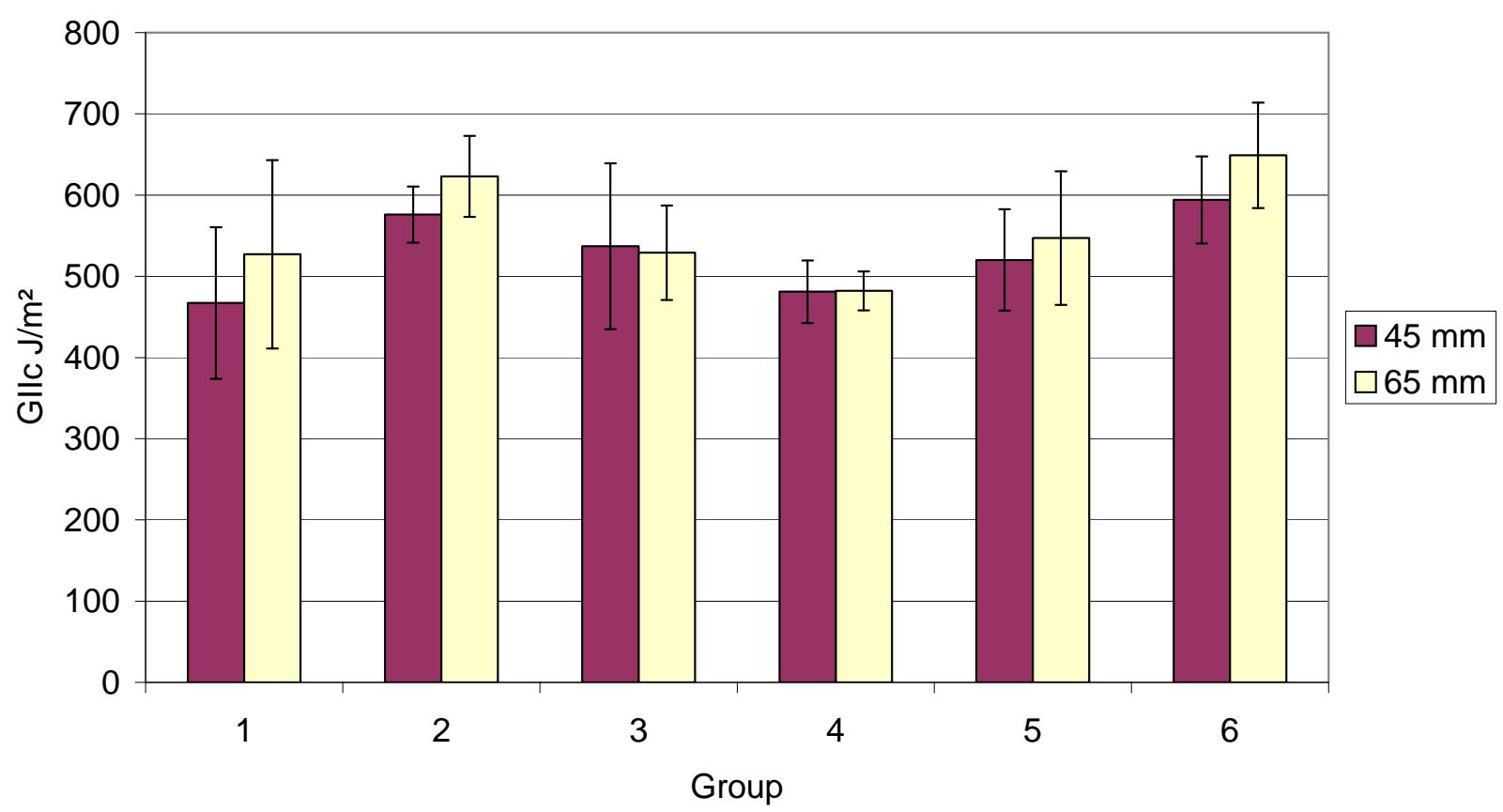

Figure 5. Propagation values measured by 6 groups at two crack lengths for carbon/epoxy,

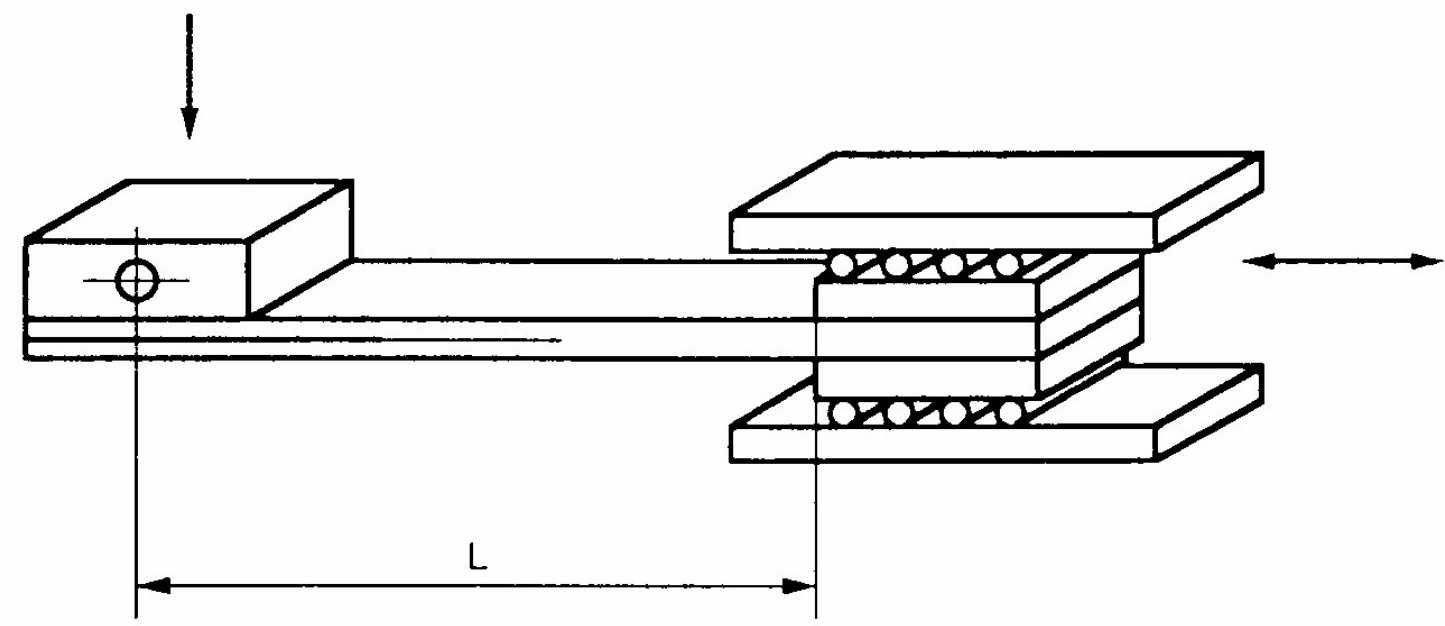

Figure 6: Schematic of the End Loaded Split test set-up for mode II delamination resistance testing.

Current activities within ESIS TC4 investigate the End Loaded Split (ELS) specimen for mode II testing again. This configuration (Figure 6 ) has the advantage of yielding stable delamination propagation. The specimen is clamped at one end in a sliding fixture and the load applied through one load-block. There is some early literature (see [1] for references), and recent round robin results including a clamp correction procedure and an approach for circumventing the inherent problem of visual delamination length measurement based on an approach developed for mode I [45] will be published soon [46].

Mode II tests of multidirectional glass- and carbon-fiber laminates and their analysis, complemented by extensive modelling are reported in the literature [47-49]. A dependence on the angle of the delaminating interface was observed, with increasing values of $G_{\| C}$ for increasing angle of fiber orientation. Also, a comparison between initiation values from a starter film and from mode II precrack showed significant resistance curve effects, i.e., higher $\mathrm{G}_{\| \mathrm{C}}$ values from the pre-crack.

An early attempt in 1993 within ASTM to develop a mode II fatigue test based on the ENFspecimen recommended an R-ratio of 0.1 and a test frequency of $5 \mathrm{~Hz}$. However, it was not intended for standardization and not pursued beyond the draft stage [50]. Recent research in this area again employed the ENF-specimen. The feasibility of the approach was shown and the Paris 
law dependence between lamination growth and applied $\Delta \mathrm{G}_{\|}$confirmed [51]. However, it is unlikely that this test will be developed into a standard procedure soon.

An investigation of mode II delamination of glass-fiber composites has not shown rate effects in the range between $1 \mathrm{~m} / \mathrm{min}$ and $3 \mathrm{~m} / \mathrm{s}$ [52]. Recent FE-simulations of delaminations at impact speeds up to $40 \mathrm{~m} / \mathrm{s}$ raise several questions, in particular that of the effects of friction [53] The simulations and further experimental studies may provide a basis for the future development of a high-rate mode II test procedure.

\section{MODE III TESTING}

Mode III (out-of-plane shear) testing was the subject of some interest in the late 1980's and several specimen geometries were proposed, including split cantilever beam [54] and cracked rail shear [55]. However, all of these had drawbacks and none was pursued at that time. A summary of these test methods is given in [56]. Interest revived with the introduction of the ECT (Edge Cracked Torsion) test by Lee [57] in 1993. This involves applying equal and opposite moments to the corners of rectangular specimens with a specially designed stacking sequence including $90 / 0 /+45 /-$ 45 plies and a mid-plane insert film (Figure 7).

This test has been investigated in detail with respect to friction and mode II contributions, and both were found to yield negligible contributions [58].

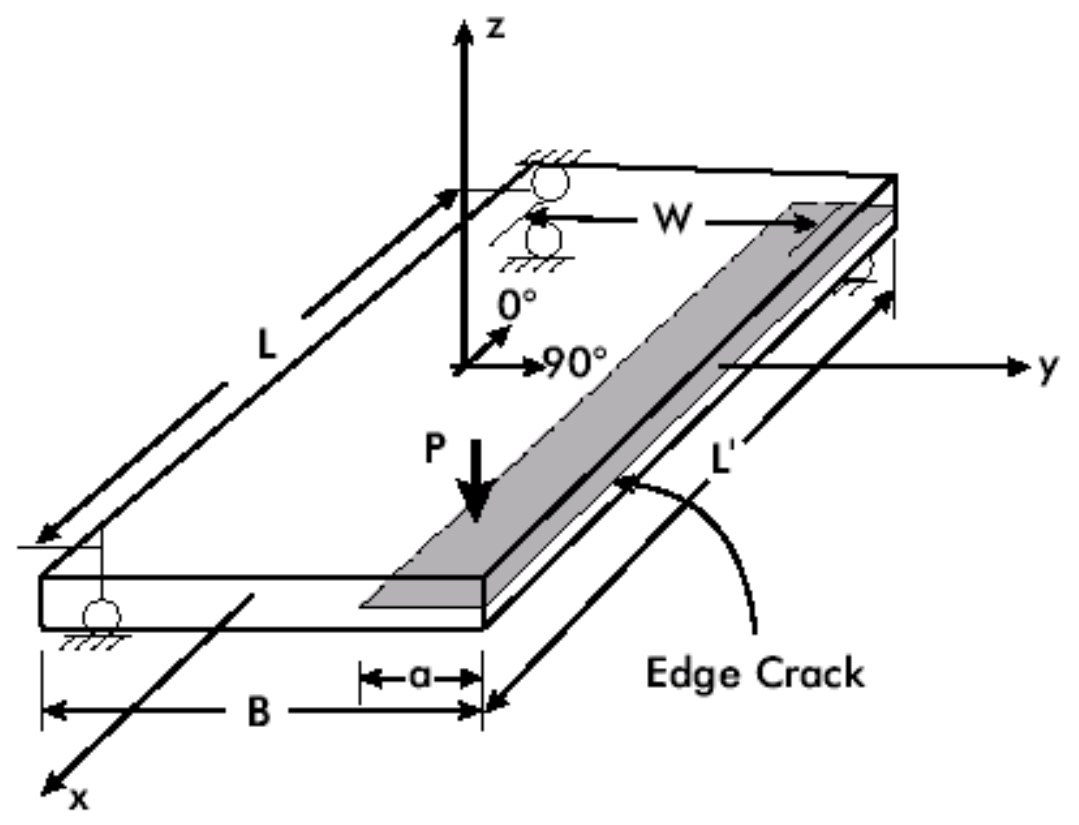

Figure 7. Mode III ECT test set-up, initial version

An ASTM D30 round robin was organized to evaluate this test on carbon/epoxy samples but the results reported in 1997 indicated large scatter and considerable non-linearity. The test frame was then modified so that load could be applied symmetrically by two pins, and a second round robin was organized. Results presented in 1999 indicated that delaminations did not always grow at the $90^{\circ} / 90^{\circ}$ interface and a significant mode II component was indicated near the loading pins. Longer test specimens were recommended to reduce the latter. Suemasu developed an alternative loading technique, using a torsion machine to twist prismatic bars with insert films and suggested that this provides more pure mode III loading [59]. Further standardization work on mode III testing has not been reported, but some more recent publications have shown results from this specimen geometry.

Ratcliffe [60] ran tests and numerical analyses. He noted a strong effect of initiation values on insert length when maximum load was used to determine $G_{\text {IIIc }}$ values. When onset of non-linearity was used values obtained were lower than $G_{\| 1}$ values for the same materials. He also underlined the need for detailed fracture surface analysis to validate the tests. These observations underline the difficulty with this specimen. Crack growth is not visible so multi-specimen testing with different initial crack lengths and post-test inspection is necessary. Li et al. [61] applied the ECT specimen to measure $G_{\text {IIIc }}$ values for E-glass/epoxy and showed that intralaminar cracks in the $90^{\circ}$ plies contributed significantly to $G_{\text {IIIc }}$ values during propagation. 
Fatigue or high-rate mode III results on composites have, to the best of our knowledge not been published in the literature, but may be the subject of current research.

\section{MIXED MODE TESTING (I/II, I/III, II/III)}

The MMB (Mixed Mode Bending) test configuration, shown schematically in Figure 8, has become the accepted way of determining variable ratio mixed mode (I/II) fracture energy.

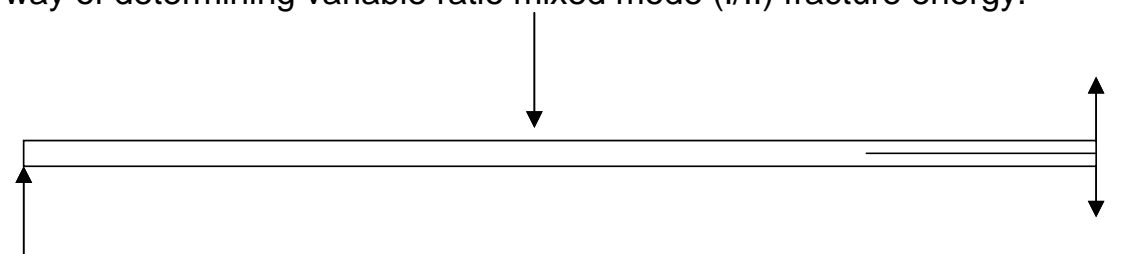

Figure 8. Schematic representation of mixed mode bending test configuration.

A standard test method [62] was introduced in 2001 and this is now widely used. The fixture proposed in the standard is a modified version of that originally proposed by Crews and Reeder in 1988 [63] as the initial version resulted in non-linearity due to large displacements [64]. The test fixture enables mixed mode ratio to be varied simply by changing the loading moment arm.

During the standardization process some modifications were introduced by Reeder, including an improved data analysis, more accurate mode ratio determination and checks on fixture alignment [65]. The data reduction is based on a corrected beam theory expression rather than compliance calibration as the crack propagation is not always stable and shifting the specimen to measure compliance for different crack lengths (as performed for ENF specimens for example) is difficult due to the bonded hinges. Bhashyan and Davidson studied MMB data analyses in some detail and their results indicated that the modified beam theory agreed well with FE analyses [66]. The determination of lever length for a required mixed mode ratio in the standard is now determined by a more accurate expression than the original simple beam equations, as round robin test results showed that mode ratios were often very different to those expected. Careful test fixture alignment was shown to be necessary to obtain reliable values as delaminations can originate at insert film corners if this was not checked. A procedure with a $0.05 \mathrm{~mm}$ feeler gauge is now included to verify alignment. Finally, lever arm weight may need to be corrected and this can complicate the analysis. A modified fixture proposed by Chen et al. [67] to reduce the influence of the weight of the lever arm on the measured toughness and simplify the analysis was not included in the standard test method but corrections are needed if the arm weighs more than $3 \%$ of the applied load.

The MMB fixture has been used in a number of recent studies. The scope of the ASTM standard is defined as "limited to use with composites consisting of unidirectional carbon fiber tape laminates with brittle and tough single-phase polymer matrices. The test is further limited to the determination of fracture toughness as it initiates from a delamination insert". However, its subsequent use has not been limited to this. For example, fracture envelopes for glass/epoxy unidirectional composites were produced by Ducept et al. [68]. Scaled-up fixtures have also been designed to allow MMB tests to be performed on woven glass fiber reinforced composites with large weave size (Figure 9). The influence of fiber orientation in carbon/epoxy laminates was examined by Kim \& Mayer [69], who showed a strong influence of fiber mismatch angle at the crack plane on crack propagation resistance. The MMB specimen has even been used to examine the influence of through-thickness reinforcement (Z-pins) on crack propagation resistance, though the authors stress that the nominal mixed mode fracture energies obtained are not material properties and should only be used as an indication of the influence of the z-fibers [70].

The success of the MMB fixture has limited the development of other specimens. The fixed ratio mixed mode ADCB (Asymmetric Double Cantilever Beam), studied extensively by the ESIS TC4 group in the 1990's, is limited as it is a single ratio of 4:3 of mode I to mode II component [1]. The ADCB-test requires a sliding fixture the same as the mode II ELS-test. Locus plots with pure mode I, pure mode II and mixed mode I/II can thus be generated with two test rigs (DCB and sliding fixture for ELS and $A D C B$ ), or, alternatively with three rigs (DCB, 4ENF, and MMB). The latter will yield a larger range of mixed-mode ratios, at the expense of an additional test fixture. However, the larger the mode II ratio in the mixed-mode test, the more the problems associated with mode II testing will come into play, too. 


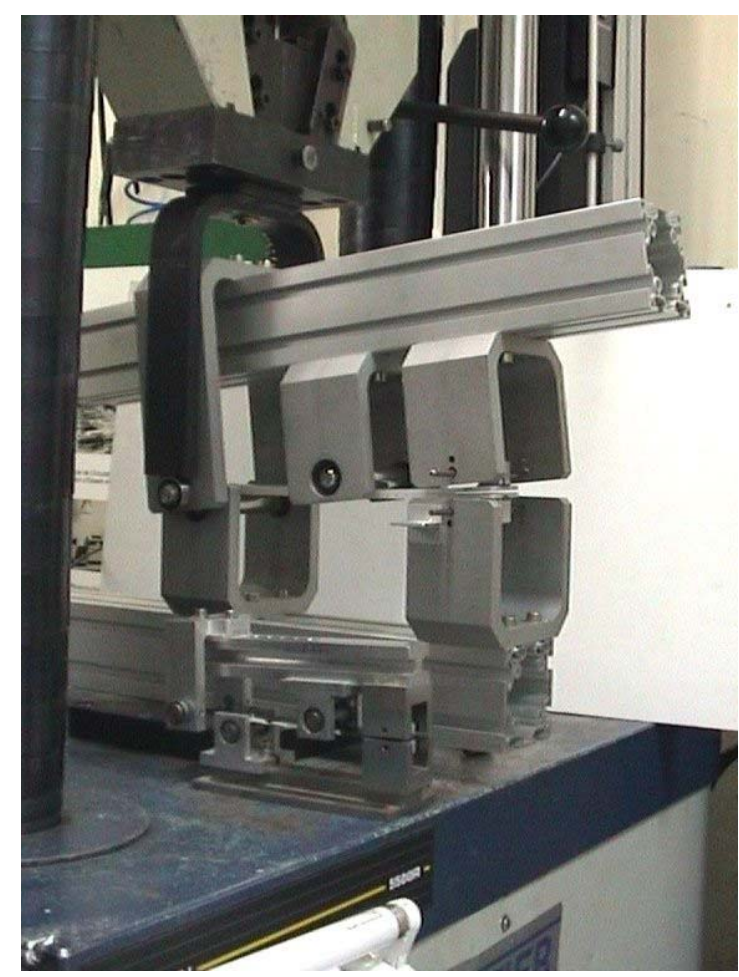

Figure 9. Scaled-up MMB fixture, shown next to standard size fixture.

One of the rare criticisms of the MMB test has been the cost of the fixture, and this has motivated a few studies of other specimen configurations. Tracy et al. [71] suggested that a single leg four point bend (SLFPB) test might provide a simpler alternative, Figure 10.

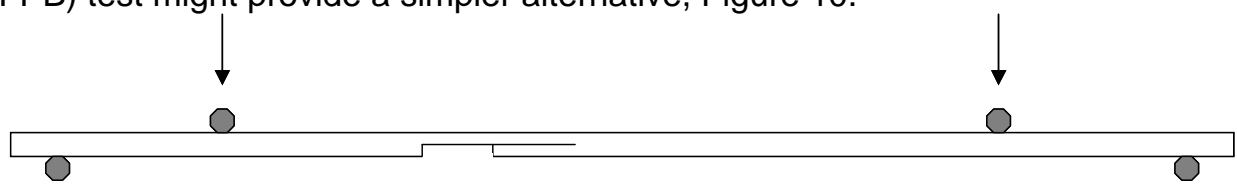

Figure 10. Schematic of the single-leg-four-point (SLFPB) specimen for mixed-mode testing.

These authors tested a configuration introducing approximately $50 \%$ mode I, $50 \%$ mode II on carbon/epoxy composites.

There has also been some further analysis of single leg bending specimens reported [72] but it seems unlikely that any of these specimens will be proposed for standardization.

Virtually all research work has focussed on mode I/II, very few studies have looked at I/III or II/III since the early work on tensile tests with special stacking sequences described previously [1].

Mixed mode delamination under fatigue loading has been investigated, e.g., by Kenane and Benzeggagh [73] for glass- and by Blanco et al. [74] for carbon-fiber laminates.

Very few studies have examined high rate mixed mode fracture. A recent publication by Wosu et al. [75] investigates dynamic delamination fracture using a split Hopkinson bar experiment and three different specimens: a) Mixed-mode open-notch flexure (MONF), b) anti-symmetric loaded endnotched flexure (MENF), and c) center-notched flexure (MCNF). The maximum impact energy has been $9.3 \mathrm{~J}$. Comparison with mixed-mode bending data showed some agreement with respect to mode II but less with mode I.

\section{OTHER ISSUES}

This section deals with issues that relate to several or all modes or loading conditions that have been discussed above, as well as with new developments that, in the admittedly subjective opinion of the authors, are expected to become important in the near future.

There is some literature on intralaminar fracture, see, e.g., [76-80], but currently, this area is not under consideration for developing standardised test methods. Testing of thick composite materials has also received some attention [81] and ASTM has issued a standard test method for translaminar fracture toughness [82] with the eccentrically-loaded single-edge notch tension ESE(T) specimen. 
Woven reinforcement in composites can provide a bridge from two- to three-dimensionally reinforced laminates [83]. A major development since the last review paper has been the introduction of composites with through-the-thickness reinforcements. Stitching [84-88], Z-pinning [89-90] (Figure 11) and braiding [18, 91] are three approaches for obtaining three-dimensional reinforced composites of which delamination resistance in mode I or II has been investigated in recent literature. Z-pinning has been introduced commercially and first composite structures with Zpins are in service in spite of concerns about their long-term behavior [92].

There are significant difficulties in the determination of fracture resistance and at present most studies simply indicate lower bound toughness values, which correspond to the strain energy release rates at which some mechanism other than delamination occurs and invalidates the analysis. There have been attempts to develop micromechanics approaches but there is presently no widely accepted method for evaluating such materials. For Z-pinned laminates, the simple model of a developing and fully developed delamination resistance [93] represents a first step towards a quantitative analysis. Acoustic Emission monitoring of delamination propagation in complex laminates (see, e.g. [33, 94]) can also yield useful information for the interpretation of the delamination resistance. Even though an apparent increase in delamination resistance has been observed, there remain questions, such as for example, the influence of three-dimensional reinforcements on fatigue and high-rate delamination behavior [95], beside the interpretation of the data. Given their technical advantages the development of appropriate evaluation methods for these materials will be essential in the next few years.

The evaluation of effects of environmental exposure on fracture mechanics data has to be evaluated also, in particular if fracture mechanics data are used in the design of composite parts or structures [3]. Ageing effects from thermal cycles (e.g., [96]) or water exposure (e.g., [97-99]) on quasi-static behavior can quite likely be assessed by testing suitably exposed specimens in a standard laboratory climate. Fatigue delamination growth at elevated temperatures has been investigated for example by Sjögren and Asp [100]. Exposure to certain media, e.g., solvents may require suitable test rigs analogous to those described for investigation of stress-corrosion cracking effects [101]. The same holds for evaluation of delamination resistance at low temperatures, e.g., for aerospace applications [102].

Delamination resistance determination on structural parts such as filament-wound composite pipes has been attempted by some researchers. Mode I delamination (see e.g. [103, 104]), mode II (see, e.g., [105, 106]), and mixed mode I/II delaminations (see, e.g., [107]) have been investigated. Another area in which delamination tests are being used is in sandwich structures, for which interface crack resistance is of primary importance. Tests have been developed to characterize this failure mode under different loading conditions [108]. The main application of testing in this area is quite likely design verification; examples of this have recently been described by e.g., Zou et al. [109], and Savage [110].

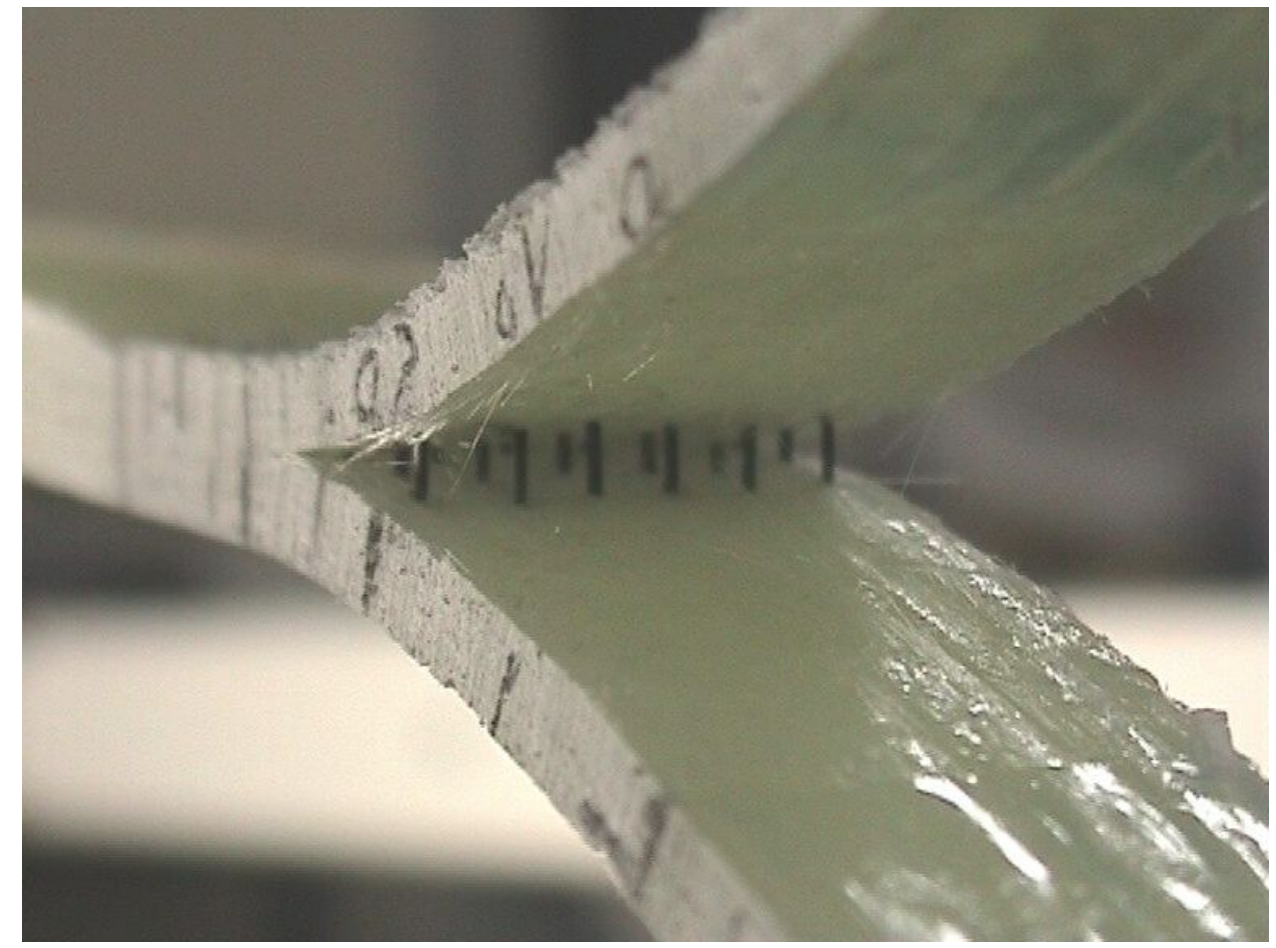

Figure 11: DCB-specimen of Z-pinned GFRP laminate in mode I delamination test 
The use of two parameter models to represent fracture in FRPC has become increasingly popular since the last review by the present authors. Such models are based on the approach that two parameters exist to describe the fracture process, namely $\mathrm{Gc}$ and $\sigma_{\max }$. The $\mathrm{Gc}$ value is obtained from the delamination test under the appropriate mode of loading (i.e. mode I, II, III or mixed) and the $\sigma_{\max }$ value (which is assumed to be the critical limiting maximum value of the stress in the damage zone ahead of the crack) is required from an independent test but is often assumed. The cohesive zone model is a general representation of a two parameter failure criteria, and these models have been applied extensively to describe delamination fracture in recent years [111]. A traction-separation curve is used to describe the fracture, with the area under the curve representing Gc. The model is usually implemented using FEA. A recent paper [112] investigated the use of a cohesive zone model to describe fracture in three different fracture mechanics test specimens, including a FRPC in mode I. The authors found that the cohesive zone model description of fracture was close to that observed experimentally, and to that predicted analytically [113], but the physical significance of the value of $\sigma_{\max }$ employed was found to be questionable and there was a lack of uniqueness in the solutions obtained. Whether $\sigma_{\max }$ represents a true characteristic material fracture criterion is still an open question.

The delamination resistance of most composites with modified polymer matrix, such as e.g., recently developed nano-modified or nano-structured polymers can quite likely be determined according to the existing procedures [114].

An interesting suggestion is the use of doubler reinforcement plates for delamination resistance testing in cases where premature failure of one specimen arm is observed. This may occur in thin specimens or in high toughness laminates [115]. A similar concept has been used by Kim et al. [116] to study mode I delamination resistance of weft-knitted fabric composites.

\section{SUMMARY AND OUTLOOK}

Summarizing the current status of standardised tests for determination of the delamination resistance of fiber-reinforced polymer-matrix composites (FRPC), significant progress within the last five to eight years can be noted. First there are now standardised test methods published by recognized organisations for a number of different cases. Considerable research has been performed investigating issues related to either different types of lay-up or to different types of loading. Specifically, the important questions of rate-dependent and fatigue behavior of laminates are currently being addressed by committees dealing with the development of standardized test methods.

Progress has also been made with respect to analysis and interpretation of the data. Several test methods now offer spreadsheets for data analysis, including various correction factors and offering the opportunity to compare different approaches for analyses (e.g., beam theory based versus experimental compliance). Currently, the exact measurement of the delamination length has become a focus of attention and recent models may provide operator-independent determination of effective crack lengths. Modelling efforts may help to further improve understanding of various factors affecting the measurements.

While not currently being considered for standardisation, development of procedures for determining the fracture toughness of parts or elements made of FRPC has also advanced. On the other hand, few examples of the application of fracture mechanics data in design are available in the published literature.

Developing suitable testing and analysis procedures for the determination of the delamination resistance of multi-directional laminates under quasi-static and fatigue loading in the different modes remains a challenge.

\section{ACKNOWLEDGMENTS}

Current and past members of Technical Committee 4 Polymers and Composites of the European Structural Integrity Society are acknowledged for discussions and for providing references. Profs J.G. Williams and A. Pavan as chairmen of TC4 have provided valuable contributions during the development of the various test procedures, and Drs A.J. Cervenka, G. Pinter, and D.D.R. Cartié are acknowledged as past and current session leaders, respectively, in the development of laminates test methods within TC4. 
[1] Davies P., Blackman B.R.K., Brunner A.J. Standard Test Methods for Delamination Resistance of Composite Materials: Current Status. Applied Composite Materials, 1998;5(6):345-364.

[2] Tay T.E. Characterization and analysis of delamination fracture in composites - a review of developments from 1990 to 2001. Applied Mechanics Reviews. 2003;56(1):1-23.

[3] Martin R.H. Incorporating interlaminar fracture mechanics into design. Proceedings of the Institution of Mechanical Engineers, Part L, Journal of Materials: Design and Applications. 2000;214(2):91-97.

[4] Yoshihara $\mathrm{H}$. Mode II initiation fracture toughness analysis for wood obtained by 3-ENF test. Composites Science and Technology. 2005;65(14):2198-2207.

[5] Fracture Mechanics Test Methods for Polymers, Adhesives and Composites (Moore D.R., Pavan A., Williams J.G., eds.), ESIS Publication No. 28, Elsevier. 2001:271-359.

[6] Fibre-reinforced plastic composites - Determination of mode I interlaminar fracture toughness, $\mathrm{G}_{\mathrm{IC}}$, for unidirectionally reinforced materials, 15024, International Organisation for Standardisation, ISO. 2001.

[7] Standard Test Method for Mode I Interlaminar Fracture Toughness of Unidirectional FibreReinforced Polymer Matrix Composites, D 5528, American Society for Testing and Materials International, ASTM. 1994.

[8] Testing methods for interlaminar fracture toughness of carbon fibre reinforced plastics, K7086, Japanese Standards Association, JSA. 1993.

[9] Glessner A.L., Takemori M.T., Vallance M.A., Gifford S.K. Mode I Interlaminar Fracture Toughness of Undirectional Carbon-Fiber Composites Using a Novel Wedge-Driven Delamination Design, in: Composites Materials: Fatigue and Fracture, $2^{\text {nd }}$ Volume, Lagace P.A., editor, American Society for Testing and Materials, ASTM. 1989,STP 1012:181-200.

[10] Brunner, A.J. Experimental Aspects of Mode I and Mode II Fracture Toughness Testing of Fiber-reinforced Polymer-Matrix Composites, Computer Methods in Applied Mechanics and Engineering, 2000:185(2-4):161-172.

[11] Sela N., Ishai O. Interlaminar fracture toughness and toughening of laminated composite materials: a review. Composites. 1989;20(5):423-435.

[12] Wang Y., Zhao D. Characterization of interlaminar fracture behaviour of woven fabric reinforced polymeric composites. Composites. 1995;26(2):115-124.

[13] Varelidis P.C., Papakostopoulos D.G., Pandazis C.I., Papaspyrides C.D. Polyamide coated Kevlar $^{\mathrm{TM}}$ fabric in epoxy resin: mechanical properties and moisture absorption studies. Composites Part A: applied science and manufacturing. 2000;A31(6):549-558.

[14] Huang B.-Z., Hu X.-Z., Liu J. Modelling of inter-laminar toughening from chopped Kevlar fibers. Composites Science and Technology. 2004;64(13-14):2165-2175.

[15] Gassan J., Bledzki A.K. Possibilities for improving the mechanical properties of jute/epoxy composites by alkali treatment of fibres. Composites Science and Technology. 1999;59(9):13031309.

[16] Singleton A.C.N., Baillie C.A., Beaumont P.W.R., Peijs T. On the mechanical properties, deformation and fracture of a natural fibre/recycled polymer composite. Composites Part B: engineering. 2003;B34(6):519-526.

[17] Benevolenski O.I., Karger-Kocsis J., Czigány T., Romhány G. Mode I fracture resistance of glas fiber mat-reinforced polypropylene composites at various degree of consolidation. Composites Part A: applied science and manufacturing. 2003;A34(3):267-273.

[18] Mouritz A.P., Baini C., Herszberg I. Mode I interlaminar fracture toughness properties of advanced textile fibreglass composites. Composites Part A. applied science and manufacturing. 1999;A20(7):859-870.

[19] Kim J., Shioya M., Kobayashi H., Kaneko J., Kido M. Mechanical properties of woven laminates and felt composites using carbon fibers. Part 2: interlaminar properties. Composites Science and Technology. 2004;64(13-14):2231-2238.

[20] Choi N.S., Kinloch A.J., Willams J.G. Delamination Fracture of Multidirectional CarbonFiber/Epoxy Composites under Mode I, Mode II and Mixed Mode I/II Loading. Journal of Composite Materials. 1999;33(1):73-100.

[21] de Morais A.B. Double cantilever beam testing of multidirectional laminates. Composites Part A: applied science and manufacturing. 2003;A34(12):1135-1142.

[22] Pereira A.B., de Morais A.B. Mode I interlaminar fracture of carbon/epoxy multidirectional laminates. Composites Science and Technology. 2004;64(13-14):2261-2270

[23] Brunner A.J., Blackman B.R.K. Delamination fracture in cross-ply laminates: What can be learned from experiment? Proceedings $3^{\text {rd }}$ ESIS TC4 Conference in: Fracture of Polymers, 
Composites and Adhesives (Blackman B.R.K., Williams J.G., Pavan A., eds.), ESIS-Publication No. 32, Elsevier 2003:433-444.

[24] de Morais A.B., de Moura M.F., Marques A.T., de Castro P.T. Mode-I interlaminar fracture of carbon/epoxy cross-ply composites. Composites Science and Technology. 2002;62(5):679-686.

[25] Brunner A.J., Flüeler P. Prospects in fracture of 'engineering' laminates. Engineering Fracture Mechanics. 2005;72(6):899-908.

[26] Standard Test Method for Mode I Fatigue Delamination Growth Onset of Unidirectional FiberReinforced Polymer Matrix Composites, American Society for Testing and Materials International, ASTM, 1997.

[27] Hojo M., Tanaka K., Gustafson C.G., Hayashi R. Effect of stress ratio on near-threshold propagation of delamination fatigue cracks in unidirectional CFRP. Composites Science and Technology. 1987;29(4):273-292.

[28] Hojo M., Ochiai S., Aoki T., Ito H. New simple and practical test method for interlaminar fatigue threshold in CFRP laminates. Proceedings $2^{\text {nd }}$ Conference on Composites Testing and Standardisation (Hogg P.J., Schulte K. Wittich H., eds.) 1994:553-561.

[29] Andersons J., Hojo M., Ochiai S. Empirical model for stress ratio effect on fatigue delamination growth rates in composite laminates. International Journal of Fatigue. 2004;26(6):597-604.

[30] Shivakumar K., Chen H., Abali F., Le D., Davis C. A total fatigue life model for mode I delaminated composite laminates. International Journal of Fatigue. 2006;28(1):33-42.

[31] Gregory J.R., Spearing S.M. A fiber bridging model for fatigue delamination in composite materials. Acta Materialia. 2004;52(19):5493-5502.

[32] Kusaka T., Hojo M., Mai Y.-W., Kurokawa T., Nojima T., Ochiai S. Rate dependence of mode I fracture behaviour in carbon-fibre/epoxy composite laminates. Composites Science and Technology. 1998;58(3-4):591-602.

[33] Benmedakhene S., Kenane M., Benzeggagh M.L. Initiation and growth of delamination in glas/epoxy composites subjected to static and dynamic loading by acoustic emission monitoring. Composites Science and Technology. 1999;59(2):201-208.

[34] Naik N.K., Shrirao P., Reddy B.C.K. Ballistic impact behaviour of woven fabric composites: Formulation. International Journal of Impact Engineering. 2006;32(9):1521-1552.

[35] see discussion and reference [7] in O'Brien T.K. Interlaminar fracture toughness: the long and winding road to standardization. Composites Part B: engineering. 1998;29B(1):57-62.

[36] Martin R., Davidson B.D. Mode II fracture toughness evaluation using a four point bend end notch flexure test. Proceedings $4^{\text {th }}$ International Conference on Deformation and Fracture of Composites, Institute of Materials. 1997:243-252.

[37] Davies P., Sims G.D., Blackman B.R.K., Brunner A.J., Kageyama K., Hojo M., Tanaka K., Murri G., Rousseau C., Gieseke B., Martin R.H. Comparison of test configurations for the determination of $G_{\| l}$ of unidirectional carbon/epoxy composites, an international round robin. Plastics, Rubber and Composites. 1999;28(9):432-437.

[38] Davies P. Summary of results from second VAMAS mode II round robin test exercise using the 4ENF specimen. IFREMER report ref. TMSI/RED/MS 99.82, July 1999.

[39] Martin R.H., Elms T., Bowron S. Characterization of mode II delamination using the 4ENF. Proceedings $4^{\text {th }}$ European Conference on Composites Testing \& Standardization, 1998:161-170.

[40] Schuecker C., Davidson B.D. Evaluation of the accuracy of the four point bend end-notched flexure test for mode II delamination toughness determination. Composites Science and Technology. 2000;60(11):2137-2146.

[41] Davies P., Casari P., Carlsson L.A. Influence of fibre volume fraction on the mode II interlaminar fracture toughness of glass/epoxy using the 4ENF specimen. Composites Science and Technology. 2005;65(2):295-300.

[42] Davidson B.D. Four point bend end-notched flexure (4ENF) test standardization update. Presentation at ASC/ASTM D30 Joint $19^{\text {th }}$ Tech Conference, October 2004.

[43] Davidson B.D., Sun X.K. Effects of friction, geometry and fixture compliance on the perceived toughness from three- and four- point bend end-notched flexure tests. Journal of Reinforced Plastics and Composites. 2005;24(15):1611-1628.

[44] Carlsson L.A., Gillespie J.W. Jr, Pipes R.B. On the analysis and design of the end notched flexure (ENF) specimen for mode II testing. Journal of Composite Materials. 1986;20(6):594-604.

[45] Brunner A.J., Blackman B.R.K., Williams J.G. Calculating a damage parameter and bridging stress from $G_{I C}$ delamination tests on fibre composites. Composites Science and Technology. 2006;66(6):785-795.

[46] Blackman B.R.K., Brunner A.J., Williams J.G. Determination of the mode II fracture resistance in fibre composites and joints via a crack length independent technique. Engineering Fracture Mechanics. 2006 (at press).

[47] de Morais A.B. Analysis of mode II interlaminar fracture of multidirectional laminates, Composites Part A. applied science and manufacturing. 2004;A35(1):51-57. 
[48] Pereira A.B., de Morais A.B. Mode II interlaminar fracture of glass/epoxy multidirectional laminates. Composites Part A. applied science and manufacturing. 2004;A35(2):265-272.

[49] Pereira A.B., de Morais A.B., Marquez A.T., de Castro P.T. Mode II interlaminar fracture of carbon/epoxy multidirectional laminates. Composites Science and Technology. 2004;64(1011):1653-1659.

[50] A protocol for interlaminar fatigue fracture testing, End-Notched Flexure (ENF) ASTM, first revision July 1994:1-11.

[51] Beghini M., Bertini L., Forte P. Experimental investigation on the influence of crack front to fiber orientation on fatigue delamination growth rate under mode II. Composites Science and Technology. 2006;66(2):240-247.

[52] Compston P., Jar P.-Y.B., Burchill P.J., Takahashi K. The effect of matrix toughness and loading rate on the mode II interlaminar fracture toughness of glass-fibre/vinyl-ester composites. Composites Science and Technology. 2001;61(2):321-333.

[53] Dwivedi S.K., Espinosa H.D. Modeling dynamic crack propagation in fiber reinforced composites including frictional effects. Mechanics of Materials. 2003;35(3-6):481-509.

[54] Donaldson S.L. Mode III interlaminar fracture characterization of composite materials. Composites Science and Technology. 1988;32(3):225-249.

[55] Becht G., Gillespie J.W. Jr. Design and analysis of crack rail shear specimen for mode III interlaminar fracture. Composites Science and Technology..1988;31(2):143-157.

[56] Farshad M., Flüeler P. Investigation of mode III fracture toughness using an anti-clastic plate bending method. Engineering Fracture Mechanics 1998;60(5-6):597-603.

[57] Lee S.M. An edge crack torsion method for mode III delamination fracture toughness. Journal of Composite Technology \& Research. 1993;15(3):193-201.

[58] Zhao D. Wang Y. Mode III fracture behaviour of laminated composite with edge crack in torsion. Theoretical and Applied Fracture Mechanics. 1998;29(2):109-123.

[59] Suemasu H. An experimental method to measure the mode III interlaminar fracture toughness of composite laminates. Composites Science and Technology. 1999;59(7):1015-1021.

[60] Ratcliffe J.G. Characterization of the Edge Crack Torsion (ECT) test for mode III fracture toughness measurement of laminated composites. NASA Technical Memorandum NASA/TM-2004213269, September 2004.

[61] Li X., Carlsson L.A., Davies P. Influence of fibre volume fraction on mode III interlaminar fracture toughness of glass/epoxy composites. Composites Science and Technology. 2004;64(9):1279-1286.

[62] Standard test method for Mixed Mode I-Mode II interlaminar fracture toughness of unidirectional fiber reinforced polymer matrix composites, ASTM D6671, American Society for Testing and Materials.

[63] Crews J.H., Reeder J.R. A mixed mode bending apparatus for delamination testing. NASA Technical Memorandum 1000662, 1988.

[64] Reeder J.R., Crews Jr J.H. Non-linear analysis and redesign of the mixed mode bending delamination test. NASA Technical Memorandum 102777, 1991.

[65] Reeder J.R. Refinements to the mixed mode bending test for delamination toughness. Journal of Composites Technology \& Research. 2003;25(4):191-195.

[66] Bhashyan S., Davidson B.D. Evaluation of data reduction methods for the mixed mode bending test. AIAA Journal. 1997;35:546-552.

[67] Chen J.H., Sernow R., Schulz E., Hinrichsen G. A modification of the mixed-mode bending test apparatus. Composites Part A: applied science and manufacturing. 1999;30(7):871-877.

[68] Ducept F., Davies P., Gamby D. Mixed mode failure criteria for a glass/epoxy composite and an adhesively bonded composite/composite joint. International Journal of Adhesion and Adhesives. 2000;20(3):233-244.

[69] Kim B.W., Mayer A.H. Influence of fiber direction and mixed-mode ratio on delamination fracture toughness of carbon/epoxy laminates. Composites Science and Technology. 2003;63(5):695-713.

[70] Rugg K.L., Cox B.N., Massabo R. Mixed mode delamination of polymer composite laminates reinforced through the thickness by z-fibers. Composites Part A: applied science and manufacturing. 2002;33(2):177-190.

[71] Tracy G.D., Feraboli P., Kedward K.T. A new mixed mode test for carbon/epoxy composite systems. Composites Part A: applied science and manufacturing. 2003;A34(11):1125-1131.

[72] Szekrenyes A., Uj J. Beam and finite element analysis of quasi-unidirectional composite SLB and ELS specimens. Composites Science and Technology. 2004;64(15):2393-2406.

[73] Kenane M., Benzeggagh M.L. Mixed-mode delamination fracture toughness of unidirectional glass/epoxy composites under fatigue loading. Composites Science and Technology. 1997;57(5):597-605. 
[74[ Blanco N., Gamstedt E.K., Asp L.E., Costa J. Mixed-mode delamination growth in carbon-fibre composite laminates under cyclic loading. International Journal of Solids and Structures. 2004;41(15):4219-4235.

[75] Wosu S.N., Hui D., Dutta P.K. Dynamic mixed-mode I/II delamination fracture and energy release rate of unidirectional graphite/epoxy composite. Engineering Fracture Mechanics. 2005;72(10):1531-1558.

[76] Humer K., Tschegg E.K., Spießberger S.M., Weber H.W. Fracture mechanical characterization of fibre reinforced plastics in the intralaminar crack opening mode (mode I) and in the shear mode (mode II). Cryogenics. 1998;38(1):69-74.

[77] Sorensen B.F., Jacobson T.K. Large-scale bridging in composites: R-curves and bridging laws. Composites Part: applied science and manufacturing. 1998;29A(11):1443-1451.

[78] Iwamoto M., Ni Q.-Q., Fujiwara T., Kurashiki K. Intralaminar fracture mechanism in unidirectional CFRP composites: Part I: Intralaminar toughness and AE characteristics. Engineering Fracture Mechanics. 1999;64(6):721-745.

[79] Iwamoto M., Ni Q.-Q., Fujiwara T., Kurashiki K. Intralaminar fracture mechanism in unidirectional CFRP composites: Part II: Analysis. Engineering Fracture Mechanics. 1999;64(6):747-764

[80] Jose S., Ramesh Kumar R., Jana M.K., Venkateswara Rao G. Intralaminar fracture toughness of a cross-ply laminate and its constituent sub-laminates. Composites Science and Technology. 2001;61(8):1115-1122.

[81] El-Hajjar R., Haj-Ali R. Mode-I fracture toughness testing of thick section FRP composites using the ESE(T) specimen. Engineering Fracture Mechanics. 2005;72(4):631-643.

[82] Standard test method for translaminar fracture toughness of laminated and pultruded polymer matrix composite materials, E1922, American Society for Testing and Materials, ASTM. 2004.

[83] Tanzawa Y., Watanabe N., Ishikawa T. Interlaminar fracture toughness of 3-D orthogonal interlocked fabric composites. Composites Science and Technology. 1999;59(8):1261-1270.

[84] Ishai O. Interlaminar fracture toughness of selectively stitched thick carbon fibre polymer fabric composite laminates. Plastics, Rubber and Composites. 2000;29(3):134-143.

[85] Tsai G.C., Chen J.-W. Effect of stitching on mode I strain energy release rate. Composite Structures. 2005;69(1):1-9.

[86] Dransfield K.A., Jain L.K., Mai Y.-W. On the effects of stitching in CFRPs -I. Mode I delamination toughness. Composites Science and Technology. 1998;58(6):815-827.

[87] Dransfield K.A., Jain L.K., Mai Y.-W. On the effects of stitching in CFRPs -II. Mode II delamination toughness. Composites Science and Technology. 1998;58(6):829-837.

[88] Chen L., Ifju P.G., Sankar B.V. Analysis of mode I and mode II tests for composites with translaminar reinforcements. Journal of Composite Materials. 2005;39(15):1311-1333.

[89] Partridge I.K., Cartié D.D.R. Delamination resistant laminates by Z-fiber® pinning. Part I manufacture and fracture performance. Composites Part $A$ : applied science and manufacturing. 2005;36(1):55-64.

[90] Yan W., Liku H.-Y. Mai Y.-W. Mode II delamination toughnes of Z-pinned laminates. Composites Science and Technology. 2004;64(13-14):1937-1945

[91] Tang G., Yan Y., Chen X., Zhang J., Xu B., Feng Z. Dynamic damage and fracture mechanism of three-dimensional braided carbon fiber / epoxy resin composites. Materials and Design. 2001;22(1):21-25.

[92] Sweeting R.D., Thomson R.S. The effect of thermal mismatch on Z-pinned laminated composite structures. Composite Structures. 2004;66(1-4):189-195.

[93] Robinson P., Das S. Mode I DCB testing of composite laminates reinforced with Z-direction pins: a simple model for the investigation of data reduction strategies. Engineering Fracture Mechanics. 2004;71(3):345-364. and Robinson P., Das S. Erratum. Engineering Fracture Mechanics. 2004;71(16-17):2561.

[94] Cartié D.D.R, Brunner A.J., Partridge I.K. Effects of Mesostructure on Crack Growth Control Characteristics in Z-pinned Laminates. Proceedings $3^{\text {rd }}$ ESIS Conference on Fracture of Polymers, Composites and Adhesives (B.R.K. Blackman, J.G. Williams, A. Pavan, eds.), ESIS Publication No. 23, Elsevier. 2005:503-514.

[95] Shah Khan M.Z., Mouritz A.P. Fatigue behaviour of stitched GRP laminates. Composites Science and Technology. 1996;56(6):695-701.

[96] Dlouhy I., Chlup Z., Boccaccini D.N., Atiq S., Boccaccini A.R. Fracture behaviour of hybrid glass matrix composites: thermal ageing effects. Composites Part A. applied science and manufacturing. 2001;A34(12):1177-1185.

[97] Hodzic A., Kim J.K., Lowe A.E., Stachurski Z.H. The effect of water aging on the interphase region and interlaminar fracture toughness in polymer-glass composites. Composites Science and Technology. 2004;64(13-14):2185-2195. 
[98] Davies P., Pomiès F., Carlsson L.A. Influence of water and accelerated aging on shear fracture properties of glass/epoxy composite. Applied Composite Materials. 1996;3(2):71-87.

[99] Davies P., Pomiès F., Carlsson L.A. Influence of water absorption on transverse tensile properties and shear fracture toughness of glass/polypropylene. Journal of Composite Materials. 1996;30(9):1004-1019.

[100] Sjögren A., Asp L.E. Effects of temperature on delamination growth in a carbon/epoxy composite under fatigue loading. International Journal of Fatigue. 2002;24(2-4):179-184.

[101] Kumosa L., Kumosa M., Armentrout D. Resistance to stress corrosion cracking of unidirectional ECR-glass/polymer composites for high voltage composite insulator applications. Composites Part A. applied science and manufacturing. 2003;A34(1):1-15.

[102] Hojo M., Matsuda S., Fiedler B., Kawada T., Moriya K., Ochiai S., Aoyama H. Mode I and II delamination fatigue crack growth behaviour of alumina fiber/epoxy laminates in liquid nitrogen. International Journal of Fatigue. 202;24(2-4):109-118.

[103] Beckert W., Lauke B., Friedrich K. Delamination toughness computation for curved thermoplastic composites. Applied Composite Materials. 1995;1:395-400.

[104] Davies P., Rannou F. The effect of defects in Tubes: Part 1. Mode I delamination resistance. Applied Composite Materials. 1995;1:333-349.

[105] Ozdil F., Carlsson L.A., Li X. Characterization of mode II delamination growth in glass/epoxy composite cylinders. Journal of Composite Materials. 2000;34(4):274-298.

[106] Zou Z., Reid S.R., Soden P.D., Li S. Measurement of the critical energy release rate GIIC for filament wound GRP pipes. Composites Part A: applied science and manufacturing. 2001;A32(2):271-280.

[107] Ozdil F., Carlsson L.A. Characterization of mixed mode delamination growth in glass/epoxy composite cylinders. Journal of Composite Materials. 2000;34(5):420-441.

[108] Cantwell W.J., Scudamore R., Ratcliffe J., Davies P. Interfacial fracture in sandwich laminates. Composites Science and Technology, 1999;59(14):2079-2085.

[109] Zou Z., Reid S.R. Li S., Soden P.D. Application of a delamination model to laminated composite structures. Composite Structures. 2002;56(4):375-389.

[110] Savage G. Enhancing the exploitation and efficiency of fibre-reinforced composite structures by improvement of interlaminar fracture toughness. Engineering Failure Analysis. 2006;13(2):198209.

[111] Chen J., Crisfield M., Kinloch A.J., Busso E.P., Matthews F.L., Qiu Y. Predicting progressive delamination of composite materials specimens via interface elements. Mechanics of Composite Materials and Structures. 1999;6(4):301-317.

[112] Blackman, B.R.K., Hadavinia, H., Kinloch, A.J., Williams, J.G. The use of a cohesive zone model to study the fracture of fibre composites and adhesively-bonded joints. International Journal of Fracture. 2003;119(1):25-46.

[113] Williams J.G., Hadavinia H. Analytical solutions of cohesive zone models. Journal of the Mechanics and Physics of Solids. 2002;50(4):809-825.

[114] Haque A., Shamsuzzoha M. Hussain F., Dean D. S2-glass/epoxy polymer nanocomposites: manufacturing, structures, thermal and mechanical properties. Journal of Composite Materials. 2003;37(20):1821-1837.

[115] Reeder J.R:, Demarco K., Whitley K.S. The use of doubler reinforcement in delamination toughness testing. Composites Part A: applied science and manufacturing. 2004;A35(11):13371344.

[116] Kim K.-Y., Curiskis J.I., Ye L., Fu S.-Y. Mode-I interlaminar fracture behaviour of weft-knitted fabric reinforced composites. Composites Part A: applied science and manufacturing. 2005;A36(7):954-964. 